\title{
Erythropoietin Ameliorates Oxidative Stress and Tissue Injury following Renal Ischemia/ Reperfusion in Rat Kidney and Lung
}

\author{
Mohammad Reza Ardalan ${ }^{a}$ Rasoul Estakhric ${ }^{c}$ Babak Hajipour ${ }^{\text {h }}$ Khalil Ansarin $^{f}$ \\ Naser Ahmadi Asl ${ }^{b} \quad$ Mohammad Reza Nasirizade ${ }^{g} \quad$ Alireza Nour Azarg $^{g}$ \\ Amir Ghorbanihaghjou $^{d}$ Amir Mansour Vatankhah ${ }^{\mathrm{e}}$ Heydar Ali Esmailic $^{\mathrm{c}}$ \\ Departments of a Nephrology, ${ }^{\text {b Physiology, }}$ 'Pathology and ${ }^{\mathrm{d}}$ Biochemistry, ${ }^{\mathrm{e}}$ Drug Applied Research Center, and \\ ${ }^{\mathrm{f}}$ Tuberculosis and Lung Disease Research Center, Tabriz University of Medical Sciences, and ${ }^{9}$ Department of \\ Physiology, Faculty of Veterinary Medicine, Tabriz Branch, Islamic Azad University, Tabriz, and h Urmia University of \\ Medical Sciences, Urmia, Iran
}

\section{Key Words}

Erythropoietin • Ischemia/reperfusion • Kidney $\cdot$ Lung

\begin{abstract}
Objective: To study the effect of erythropoietin (EPO) treatment on renal and lung injury following renal ischemia/reperfusion (I/R). Materials and Methods: Thirty male Wistar rats were assigned to three groups of 10 rats each. The first group was sham-operated, the second was subjected to renal I/R (30 min of ischemia followed by $24 \mathrm{~h}$ of reperfusion). The third group was subjected to renal $\mathrm{I} / \mathrm{R}$ and treated with EPO in two doses: the first dose $1 \mathrm{~h}$ prior to ischemia $(1,000$ $\mathrm{U} / \mathrm{kg})$ and the second dose $6 \mathrm{~h}$ after ischemia $(1,000 \mathrm{U} / \mathrm{kg})$. Results: The renal and lung tissue injury index, tissue serum blood urea nitrogen and creatinine $(\mathrm{Cr})$ were higher in the renal I/R group compared to the renal I/R + EPO group; the difference was statistically significant $(p<0.05)$. Kidney and lung tissue glutathione peroxidase and superoxide dismutase levels were higher in the renal I/R + EPO group than the renal I/R group; the difference was also statistically significant $(p<0.05)$. Conclusion: The data showed that EPO
\end{abstract}

\section{KARGER}

Fax +4161306 1234

E-Mail karger@karger.ch

www.karger.com
(C) 2012 S. Karger AG, Basel

1011-7571/13/0221-0070\$38.00/0

Accessible online at:

www.karger.com/mpp pretreatment could be effective in reducing renal and lung injury following renal $I / R$ and could improve the cellular antioxidant defense system. Hence EPO pretreatment may be effective for attenuating renal and lung injury after renal I/Rinduced injury during surgical procedures, hypotension, renal transplantation and other conditions inducing renal I/R.

Copyright @ 2012 S. Karger AG, Basel

\section{Introduction}

Renal ischemia/reperfusion (I/R) injury occurring after hemorrhagic shock or major cardiovascular surgery and renal transplantation contributes to kidney dysfunction and patient morbidity and it is the most common cause of delayed graft function or organ failure [1]. Reperfusion of previously ischemic renal tissue initiates complex cellular events that result in injury and the eventual death of renal cells [2]. Although reperfusion is essential for the survival of ischemic tissue, there is evidence that reperfusion itself causes additional cellular injury [3]. Although the pathophysiologic mechanisms 
leading to acute ischemic renal failure are not fully understood, it still continues to be associated with a high mortality rate.

The remote organ dysfunction in acute renal failure is thought to be due to humoral and/or cellular mediators circulating in the blood [4]. Cytokines that are released during I/R may play an important role in the pathogenesis of tissue injury. Tumor necrosis factor- $\alpha$, which is produced by tubular epithelial cells, as well as by activated leukocytes, induces the expression of adhesion molecules in endothelial cells, possibly enhancing leukocyte infiltration in I/R [5]. Several mechanisms such as production of reactive oxygen species (ROS) and oxidative damage are thought to directly contribute to the activation of inflammatory pathways and worsening of organ function in a variety of diseases [6,7]. Thus, ROS can be considered as signaling molecules, which trigger several pivotal mechanisms of reperfusion injury [8]. Moreover, ROS, which are produced at the sites of inflammation by neutrophils, augment the tissue injury by operating with proteases $[9,10]$. Since the lung tissue represents one of the vascular beds into which these cytokines and ROS are delivered, it would be likely to manifest a number of toxic effects of these molecules.

Erythropoietin (EPO) is produced by the kidney in response to hypoxia and stimulates erythroid progenitor cells to increase the number of mature erythrocytes within the circulation, EPO has widespread actions that reach far beyond its capacity to stimulate erythroid precursors [11]. Previous studies have shown that EPO administration decreased the levels of proinflammatory cytokines in the circulation, preserved microvascular endothelial cell integrity and reduced oxidative stress-associated lipid peroxidation [12].

The aim of this research was to study EPO pretreatment on renal I/R-induced renal and lung injury and their antioxidant enzyme contents.

\section{Materials and Methods}

Thirty male Wistar rats (210-270 g) were used for this study and they were divided into three groups of 10 rats in each group. Sham-operated: rats in this group were anesthetized and underwent laparotomy but did not experience I/R. In the second group, the rats were subjected to renal I/R, and in the third group the rats were treated with EPO in two doses: before ischemia induction ( $1 \mathrm{~h}$ with 1,000 U/kg) and the second dose $6 \mathrm{~h}$ after ischemia induction, also 1,000 U/kg. Animals were kept in accordance with the 'Principles of Laboratory Animal Care and the Guide for the Care and Use of Laboratory Animals'.

Erythropoietin and Renal Ischemia/ Reperfusion

\section{Kidney I/R Injury Animal Model}

The rats were anesthetized by intraperitoneal injection with ketamine $(50 \mathrm{mg} / \mathrm{kg}$ ) and xylazine (10 mg/kg). A midline abdominal incision was made, and both kidneys were exposed. Renal ischemia was induced by nontraumatic microvascular clamps over the pedicles for $30 \mathrm{~min}$ [13]. After clamps were released, the incision was closed in two layers with 2-0 sutures. Sham-operated animals underwent anesthesia, laparotomy, and renal pedicle dissection only. All animal procedures were performed in accordance with Tabriz Medical University guidelines for animal care. After 24-hour reperfusion, rats were anesthetized and kidneys were removed. A part of the kidney was used for histological assessment and the other for biochemical assays.

\section{Histology}

The kidney and lung tissues were fixed overnight in buffered neutral formalin, processed to paraffin wax, sectioned at $4 \mu \mathrm{m}$, and stained with hematoxylin and eosin for examination using light microscopy. The histopathologic scoring analysis was performed according to previously described methods [14, 15]. For kidney and lung, the assessment was expressed as the sum of the individual score grades from no findings (0), mild (1), moderate (2), severe (3), for four parameters from kidney sections (tubular cell swelling, cellular vacuolization, pyknotic nuclei, medullary congestion), or for six parameters from lung sections (interstitial edema, alveolar edema, alveolar hemorrhage, atelectasis, inflammatory cellular infiltration, and pulmonary congestion).

\section{Biochemical Measurements}

Creatinine and Blood Urea Nitrogen Assay. The blood was centrifuged at $1,000 \mathrm{~g}$ for $10 \mathrm{~min}$ within $1 \mathrm{~h}$ after collection. The serum samples were stored in the $-20^{\circ} \mathrm{C}$ freezer before they were analyzed. Samples were analyzed for creatinine $(\mathrm{Cr})$ and blood urea nitrogen (BUN) with commercial kits (Pars Azmoon, Tehran, Iran) by an autoanalyzer (ALCYON 300-Abbott, USA).

Glutathione Peroxidase Assay. Glutathione peroxidase (GPx) activity in kidney and lung tissues was measured using the method described by Paglia and Valentine [16]. GPx catalyzes the oxidation of glutathione by cumene hydroperoxide. In the presence of glutathione reductase and NADPH, the oxidized glutathione is immediately converted to reduced form with a concomitant oxidation of NADPH to $\mathrm{NADP}^{+}$. The decrease in absorbance at 340 nm was measured (Ransod, Randox Laboratories Ltd., Antrim, UK). Results were obtained as GPx units per milligram protein [16].

Superoxide Dismutase Assay. The kidney and lung tissues were frozen in liquid nitrogen and stored at $-20^{\circ} \mathrm{C}$ until further preparation. In order to measure antioxidant enzyme activity, the samples were homogenized in $1.15 \% \mathrm{KCl}$ solution. Superoxide dismutase (SOD) activities in liver tissue was determined by using xanthine and xanthine oxidase to generate superoxide radicals, which then reacted with 2-(4-iodophenyl)-3-(4-nitrophenol)-5phenyltetrazolium chloride to form a red formazan dye. The SOD activity was then measured by the degree of inhibition of this reaction (Ransod, Randox Laboratories Ltd.). Results were obtained as SOD units per milligram protein [17].

Data were analyzed using SPSS software 13. All data are reported as mean \pm SD. Statistical comparisons of the groups were performed followed by Tukey post test; $\mathrm{p}<0.05$ was considered significant. 


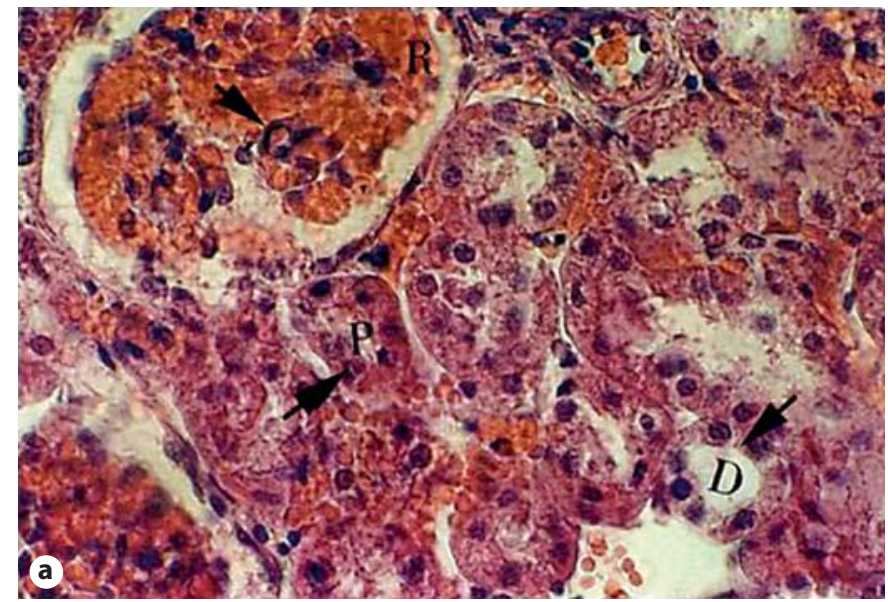

Fig. 1. a Sham-operated group. b Renal $I / R$. c $I / R+E P O$. $\mathrm{P}=$ Proximal tubule; $\mathrm{D}=$ distal tubule; $\mathrm{R}=\operatorname{red}$ blood cell; $\mathrm{G}=$ glomerulus.
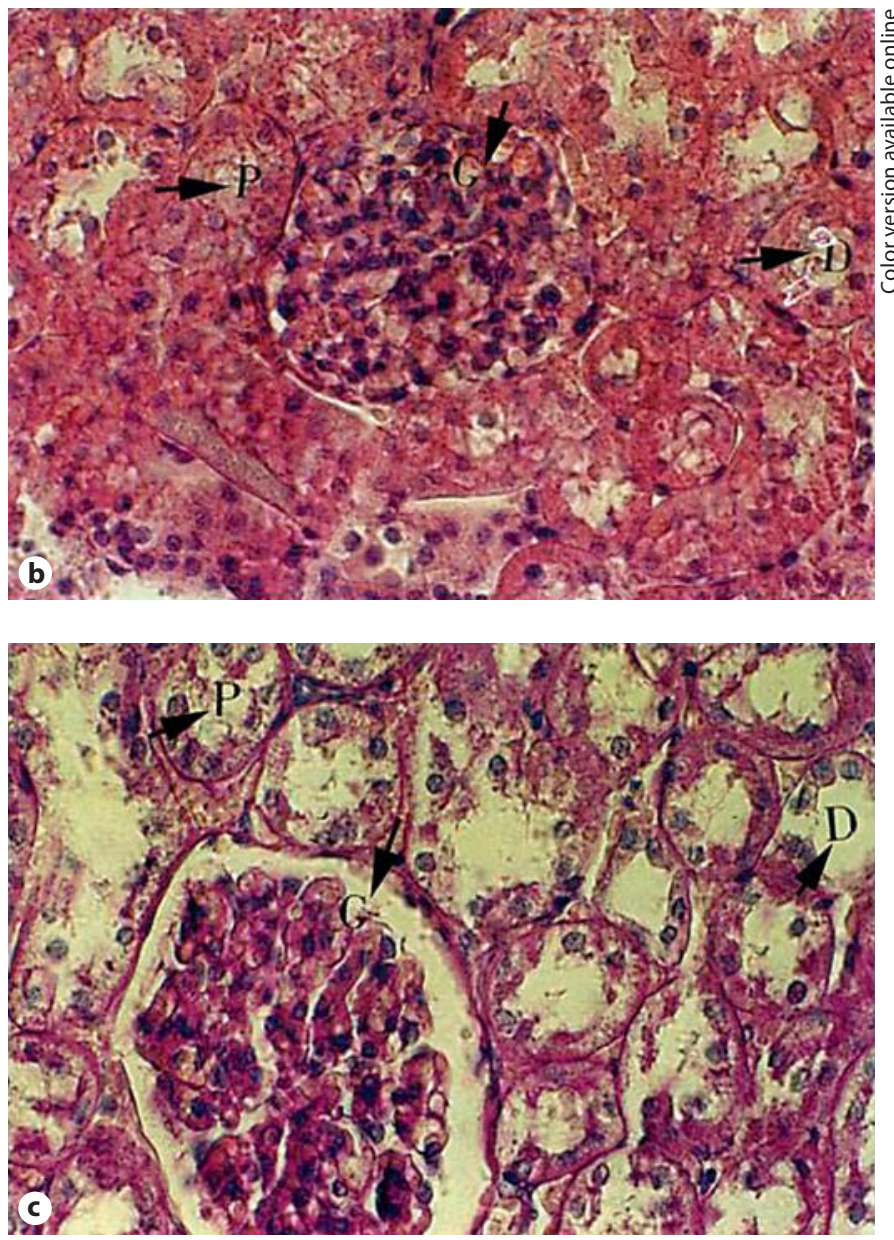

Table 1. Effect of EPO on biochemical factors after renal I/R

\begin{tabular}{|c|c|c|c|}
\hline & $\begin{array}{l}\text { Sham-operated } \\
\text { group }\end{array}$ & Renal I/R & Renal I/R+EPO \\
\hline Kidney GPx, U/mg protein & $3.22 \pm 0.31$ & $1.61 \pm 0.26$ & $2.46 \pm 0.20$ \\
\hline Lung GPx, U/mg protein & $3.54 \pm 0.54$ & $1.83 \pm 0.19$ & $2.45 \pm 0.20$ \\
\hline Kidney SOD, U/mg protein & $3.79 \pm 0.14$ & $2.17 \pm 0.17$ & $2.76 \pm 0.18$ \\
\hline Lung SOD, U/mg protein & $3.83 \pm 0.19$ & $2.73 \pm 0.23$ & $3.31 \pm 0.38$ \\
\hline BUN, mg/dl & $13.40 \pm 1.94$ & $25.60 \pm 3.64$ & $18.20 \pm 1.92$ \\
\hline $\mathrm{Cr}, \mathrm{mg} / \mathrm{dl}$ & $0.46 \pm 0.10$ & $1.94 \pm 0.42$ & $1.15 \pm 0.43$ \\
\hline
\end{tabular}

\section{Results}

\section{Renal and Lung Injury Indexes}

The renal tissue injury index was higher in the renal $\mathrm{I} / \mathrm{R}$ group $(8.60 \pm 1.14)$ compared to the renal $\mathrm{I} / \mathrm{R}+\mathrm{EPO}$ group $(6.20 \pm 1.30)$ and the difference was statistically significant $(\mathrm{p}<0.05$, table 1$)$. However, the renal injury index was significantly higher in the $\mathrm{I} / \mathrm{R}+\mathrm{EPO}$ group compared to the sham-operated group $(0.60 \pm 0.54, \mathrm{p}<$ 0.05) (fig. 1).

\section{Lung Injury Index}

The lung injury index was higher in the renal $I / R$ group $(12.80 \pm 1.92)$ compared to the renal I/R + EPO 
group $(8.60 \pm 1.67)$ and the difference was statistically significant ( $p<0.05$, table 1$)$. However, the lung injury index was higher in the I/R + EPO group compared to the sham-operated group $(1.40 \pm 0.54)$ and the difference was also statistically significant $(\mathrm{p}<0.05)$.

\section{Biochemical Assays}

Serum BUN and Cr levels were significantly higher in the renal I/R group compared to the renal I/R + EPO group ( $\mathrm{p}<0.05$, table 1$)$. The tissue GPx and SOD levels in kidney and lung tissue in the renal I/R + EPO group were significantly higher than in the renal I/R group $(\mathrm{p}<$ 0.05 , table 1 ).

\section{Discussion}

In this study, EPO pretreatment decreased renal I/Rinduced injury in kidney and lung tissues; specifically severe renal ischemia for $30 \mathrm{~min}$ followed by reperfusion after $24 \mathrm{~h}$ caused significant renal dysfunction as assessed by a marked increase in the serum concentrations of BUN and Cr. Renal I/R also resulted in renal tubular injury and alveolar damage in lung tissue as distant organ injury. Renal I/R injury increases pulmonary vascular permeability, interstitial edema, alveolar hemorrhage, and red blood cell sludging $[18,19]$. Because the lung has the largest microcapillary network in the body, it responds to circulating proinflammatory signals with activation of lung macrophages, secretion of proinflammatory cytokines, recruitment of neutrophils and macrophages, and resultant lung injury [20]. There are many similarities among the local injury pathways activated after acute pulmonary and renal injury and secondary lung injury. Renal I/R causes apoptosis and necrosis of proximal straight tubules and inflammatory infiltration of leukocytes [21].

In addition, in our study renal I/R decreased GPx and SOD as cellular antioxidant defenses both in renal and lung tissue. ROS-mediated cellular damage can be expected to occur when the oxygen is supplied to the tissue by reperfusion and ROS formation exceeds the high cellular detoxification capacity of kidneys. The pathogenesis of oxygen deprivation-induced cell injury includes release of ROS, activation of leukocytes, lipid peroxidation, disturbances of cell calcium metabolism, and loss of cell volume. Endogenous antioxidant enzymes such as SOD, catalase, and GPx protect cells from detrimental effects of ROS. Activity of these enzymes indicates the magnitude of oxidative stress that occurs during I/R injury.
ROS and ROS-mediated lipid peroxidation have been highly implicated in the pathogenesis of I/R and its complications [22].

Spandou et al. [23] have shown that EPO pretreatment attenuates renal I/R-induced kidney injury through suppression of apoptosis, and they reported that renal I/R leads to activation of nuclear factor- $\kappa \mathrm{B}$, thereby suggesting that it might be a marker of injury linked to the pathophysiology of a variety of renal disorders, including I/R, and that its inhibition prevented in vivo cell apoptosis associated with renal I/R injury. Endogenous EPO is known to be primarily produced by renal cortical fibroblasts in response to hypoxia [24]. As functional EPO receptors have been found to be expressed on renal tubular epithelial, mesangial and endothelial cells, it has been hypothesized that an important paracrine EPO axis with cytoprotective functions could occur within the kidney. During the early phase of ischemic acute renal failure, EPO expression is virtually absent whereas EPO receptor expression is well maintained [25]. The authors showed that administration of exogenous EPO in both in vitro and in vivo models of hypoxic or ischemic acute renal injury significantly hastened renal structural and functional recovery. The most well-known consequence of EPO action is stimulation of erythropoiesis, which potentially enhances tissue protection against ischemic injury by augmenting the $\mathrm{O}_{2}$-carrying capacity of blood. Bagnis et al. [26] observed that EPO may have directly acted as a growth factor on tubular cells in the cortex and outer medulla. Yazihan et al. [27] have shown that EPO decreases tumor necrosis factor- $\alpha$ production following renal $I / R$, as the most important pathways in distant organ injury of renal I/R are inflammatory pathways, blockage of inflammatory pathways by EPO may be responsible for the protective effect of EPO in lung injury following renal I/R.

\section{Conclusion}

Our data showed that EPO pretreatment was effective in reducing renal and lung injury following renal I/R and could improve the cellular antioxidant defense system, so EPO pretreatment may be effective for attenuating renal and lung injury after renal I/R-induced injury.

\section{Acknowledgment}

This research was supported by a grant from the Tuberculosis and Lung Disease Research Center, Tabriz University of Medical Sciences. 


\section{References}

1 Chok MK, Ferlicot S, Conti M, Almolki A, Dürrbach A, Loric S, Benoît G, Droupy S, Eschwège $P$ : Renoprotective potency of heme oxygenase- 1 induction in rat renal ischemiareperfusion. Inflamm Allergy Drug Targets 2009;8:252-259.

-2 Lieberthal W, Levine JS: Mechanisms of apoptosis and its potential role in renal tubular epithelial cell injury. Am J Physiol 1996; 271:477-488

3 Weight SC, Bell PR, Nicholson ML: Renal ischaemia-reperfusion injury. Br J Surg 1996; 83:162-170.

4 Zarbock A, Schmolke M, Spieker T, Jurk K, Van Aken H, Singbartl K: Acute uremia but not renal inflammation attenuates aseptic acute lung injury: a critical role for uremic neutrophils. J Am Soc Nephrol 2006;17: 3124-3131.

5 Golab F, Kadkhodaee M, Zahmatkesh M, Hedayati M, Arab H, Schuster R, Zahedi K, Lentsch $\mathrm{AB}$, Soleimani M: Ischemic and non-ischemic acute kidney injury cause hepatic damage. Kidney Int 2009;75:783-792.

-6 Guarnieri G, Biolo G, Zanetti M, Barazzoni R: Chronic systemic inflammation in uremia: potential therapeutic approaches. Semin Nephrol 2004;24:441-445.

$\checkmark 7$ Kaushal GP, Liu L, Kaushal V, Hong X, Melnyk O, Seth R, Safirstein R, Shah SV: Regulation of caspase-3 and -9 activation in oxidant stress to RTE by forkhead transcription factors, Bcl-2 proteins, and MAP kinases. Am J Physiol Renal Physiol 2004;287:1258-1268.

8 Schauer RJ, Kalmuk S, Gerbes AL, Leiderer $\mathrm{R}$, Meissner H, Schildberg FW, Messmer K, Bilzer M: Intravenous administration of glutathione protects parenchymal and non-parenchymal liver cells against reperfusion injury following rat liver transplantation. World J Gastroenterol 2004;10:864-870.

9 Halliwell B: Reactive oxygen species in living systems: source, biochemistry, and role in human disease. Am J Med 1991;91:14-22.
10 Holman RG, Maier RV: Superoxide production by neutrophils in a model of adult respiratory distress syndrome. Arch Surg 1988; 123:1491.

11 Jelkmann W: Biology of erythropoietin. Clin Investig 1994;72:3-10.

12 Tascilar O, Cakmak GK, Tekin IO, et al: Protective effects of erythropoietin against acute lung injury in a rat model of acute necrotizing pancreatitis. World J Gastroenterol 2007;13:6172-6182.

13 Pompermayer K, Souza DG, Lara GG, Silveira KD, Cassali GD, Andrade AA, Bonjardim CA, Passaglio KT, Assreuy J, Cunha FQ, Vieira MA, Teixeira MM: The ATP-sensitive potassium channel blocker glibenclamide prevents renal ischemia/reperfusion injury in rats. Kidney Int 2005;67:1785-1796.

14 Singh D, Chopra K: The effect of naringin, a bioflavonoid on ischemia-reperfusion induced renal injury in rats. Pharmacol Res 2004;50:187-193.

15 Zegdi R, Fabre O, Cambillau M, Fornès P, Tazi KA, Shen M, Hervé P, Carpentier A, Fabiani JN: Exhaled nitric oxide and acute lung injury in a rat model of extracorporeal circulation. Shock 2003;20:569-574

16 Paglia DE, Valentine WN: Studies on the quantitative and qualitative characterization of erythrocyte glutathione peroxidase. J Lab Clin Med 1967;70:158-169.

17 Sun Y, Oberley LW, Li Y: A simple method for clinical assay of superoxide dismutase. Clin Chem 1988;34:497-500.

18 Gu J, Chen J, Xia P, Tao G, Zhao H, Ma D: Dexmedetomidine attenuates remote lung injury induced by renal ischemia-reperfusion in mice. Acta Anaesthesiol Scand 2011; 55:1272-1278.

19 Kramer AA, Postler G, Salhab KF, Mendez C, Carey LC, Rabb H: Renal ischemia reperfusion leads to macrophage-mediated increase in pulmonary vascular permeability. Kidney Int 1999;55:2362-2367.
20 Rabb H, Chamoun F, Hotchkiss J: Molecular mechanisms underlying combined kidneylung dysfunction during acute renal failure. Contrib Nephrol 2001;132:41-52.

21 Sheridan AM, Bonventre JV: Cell biology and molecular mechanisms of injury in ischemic acute renal failure. Curr Opin Nephrol Hypertens 2000;9:427-434.

22 Kacmaz A, Polat A, User Y: Octreotide improves reperfusion-induced oxidative injury in acute abdominal hypertension in rats. J Gastrointest Surg 2004;8:113-119.

23 Spandou E, Tsouchnikas I, Karkavelas G, Dounousi E, Simeonidou C, Guiba-Tziampiri O, Tsakiris D: Erythropoietin attenuates renal injury in experimental acute renal failure ischaemic/reperfusion model. Nephrol Dial Transplant 2006;21:330-336.

-24 Bachmann S, Le Hir M, Eckardt KU: Co-localization of erythropoietin mRNA and ecto-5'-nucleotidase immunoreactivity in peritubular cells of rat renal cortex indicates that fibroblasts produce erythropoietin. J Histochem Cytochem 1993;41:335-341.

25 Gong $\mathrm{H}$, Wang W, Kwon TH, Jonassen T, Li C, Ring T, Frøkiaer J, Nielsen S: EPO and alpha-MSH prevent ischemia/reperfusion-induced down-regulation of AQPs and sodium transporters in rat kidney. Kidney Int 2004; 66:683-695.

-26 Bagnis C, Beaufils H, Jacquiaud C, Adabra Y, Jouanneau C, Le Nahour G, Jaudon MC, Bourbouze R, Jacobs C, Deray G: Erythropoietin enhances recovery after cisplatin-induced acute renal failure in the rat. Nephrol Dial Transplant 2001;16:932-938.

27 Yazihan N, Ataoglu H, Kavas GO, Akyurek $\mathrm{N}$, Yener B, Aydm C: The effect of K-ATP channel blockage during erythropoietin treatment in renal ischemia-reperfusion injury. J Invest Surg 2008;21:340-347. 